\title{
Seasonal and Spatial Variation of Subgrade Response
}

\author{
Mustaque Hossain ${ }^{1}$, Ph.D., P.E., Member, ASCE, Stefan Romanoschi ${ }^{2}$, Ph.D., \\ Member, ASCE, Andrew J. Gisi ${ }^{3}$ P.E.
}

\section{Abstract}

Temperature, subgrade moisture content, and Falling Weight Deflectometer (FWD)-deflection data were collected monthly on four asphalt pavement test sections in Kansas for a year. The subgrade moduli were backcalculated using the elastic layer theory. It was found that for almost all sites, the monthly variation in subgrade moisture content was not very significant over the seasons. The patterns of subgrade response, in terms of subgrade moduli versus time, simulated sine-shaped forms signifying a possible temperature effect. Higher variabilities across the site were associated with the extreme temperature conditions, usually very low or high average pavement temperatures. In all cases, the measured precipitation was nominal thereby excluding this climatic variable as a major factor. Extreme test temperatures, both high and low, result in higher variation of measured deflections and subsequently, backcalculated subgrade moduli across a site. Thus, some variabilities in backcalculated subgrade moduli can be minimized by conducting FWD tests in a moderate temperature regime. The analysis of variance (ANOVA) indicated that both seasonal and site variabilities can be significant. After correction for temperature, variations in deflections and moduli become approximately equal to the site variabilities which was also confirmed by ANOVA.

\footnotetext{
${ }^{1}$ Associate Professor, Dept. of Civil Engineering, Seaton Hall, Kansas State University, Manhattan, KS 66506.

${ }^{2}$ Visiting Assistant Professor, Dept. of Civil Engineering, Seaton Hall, Kansas State University, Manhattan, KS 66506.

${ }^{3}$ Assistant Geotechnical Engineer, Kansas Department of Transportation, Bureau of Materials \& Research, 2300 Van Buren, Topeka, KS 66611.
} 


\section{Introduction}

The most expensive structural elements of the highway system are the pavements. Several environmental variables affect pavement structural behavior and performance and in turn, pavement surface deflections measured with a deflection testing device. These variables include: (i) moisture, (ii) temperature, (iii) solar radiation and atmospheric conditions, and (iv) site geological conditions (Haas et al. 1994). The first two classes of variables are known to have significant impact on pavement structural behavior. However, to quantify the effects of seasonal variation, it is necessary to expand the general knowledge of how pavement layer properties vary over time, under different conditions, so that general models can be developed to predict the behavior of materials at a standard temperature, based on the easilyevaluated material properties and existing climatic data (Richter 1991).

The Kansas Department of Transportation (KDOT) studied the effects of these factors on the deflection basins measured by the Dynaflect, and developed correction factors to take into account the seasonal variation of layer material structural properties (Gisi 1982). KDOT currently operates two Dynatest model 8000 Falling Weight Deflectometer (FWD). Because of operational differences between the Dynaflect and the FWD, especially load magnitude and frequency, quantification of seasonal variation of FWD data was deemed necessary.

\section{Objective}

The major objective of this research project, a cooperative effort between Kansas State University and the Kansas Department of Transportation (KDOT), was to evaluate and quantify the effect of seasonal variation in material properties on the FWD-measured deflections. This paper discusses the seasonal and spatial variation of subgrade layer moduli backcalculated from the FWD-measured deflections.

\section{Methodology}

\section{Site Selection}

The sites for this research were selected based on the following factors: (i) type of pavement (flexible or rigid), (ii) type of subgrade soil (fine or coarse), (iii) average number of frost-free days, and (iv) average annual precipitation. Thirty years of climatic data (precipitation and temperature) were used to subdivide the state into three zones. Using the general soil map of Kansas, four $500-\mathrm{ft}$ long asphalt pavement sections were selected as the test sites in the middle zone of the state which somewhat represents the average climatic condition for Kansas. Two sites (K-18 \& K-113) are in northeast Kansas and two (U-160 \& U-283) in southwest Kansas. Most of the sites have silty clay soils as subgrade materials as shown in Table 1 . The table also lists the 
average annual precipitation and average daily maximum temperature for each site. The depth of frost-penetration varies from about $610 \mathrm{~mm}$ to $760 \mathrm{~mm}$.

\section{Data Collection}

The following data was collected for each site: (i) deflections using an FWD; (ii) climatological data (precipitation and temperature); surface and air temperatures during testing were obtained from the FWD sensors; and (iii) moisture contents in the subgrade using principles of time domain reflectometry (TDR). Soil-moisture observations were made bimonthly during the thaw period (February 15 - April 15) for the sites in northeast Kansas and monthly during rest of the year at all sites. Concurrent pavement deflection measurements were made using a Dynatest 8000 FWD.

\section{Field Tests and Measurements}

Moisture readings were taken at least once a month using TDR gages installed in the subgrade soil. On each site, three waveguides (three-rod type manufactured by Soilmoisture Equipment Corp.) were installed under the pavements at a spacing of 76 $\mathrm{m}$. The TDR cable tester was calibrated using soils with known dry densities (Hossain et al. 1996).

Deflection data was collected at ten locations at $15.2 \mathrm{~m}$ intervals on each test section. The first sensor was located at the center of the loading plate with six others at a uniform radial distance $300 \mathrm{~mm}$ apart. Three drops of FWD load were used for target loadings of 31,40 and $67 \mathrm{kN}$. Tests were done on the outer wheel path of the travel lane.

\section{Interrelationship Between Subgrade Moisture Content and Precipitation}

Figures 1 and 2 show the average subgrade moisture contents (from three TDR readings) at the sites in northeast and southwest Kansas, respectively. The average moisture content on K-18 varied from $23 \%$ in October to $22 \%$ in February as shown in Figure 1. One of the waveguides at this site became nonoperational in March presumably due to application of deicing salt during winter months. It was suspected that the salt changed the dielectric constants of the water resulting in no or faulty TDR measurements. Overall, this site showed no appreciable change in subgrade moisture content despite 80 to $140 \mathrm{~mm}$ precipitation during the months from April to August.

On K-113, moisture content varied from about $16 \%$ to $20 \%$ over the study period as shown in Figure 1. Higher moisture contents were observed in February and April presumably due to run-off from ice melting. After April, all sensors at this 
site became nonoperational possibly due to accumulation of salt crystals collected in winter from the deicing salt. This pavement showed a somewhat higher rate of change of subgrade moisture content during winter and spring months, as illustrated in Figure 1. It is to be noted that among all sites in this study, this is the only site on a cut section and has a very rocky, nonplastic subgrade. This may explain partly the high fluctuation of moisture content observed not only over the months, but also along the section.

Both US-160 and US-283 were selected in the same climatic zone in southwest Kansas with the same precipitation history, but the variations of the subgrade moisture content on these routes are slightly different as shown in Figure 2. The highest subgrade moisture content for US-283 occurred in September, and for US-160, in April. However, the moisture contents were relatively unchanged, varying between $13 \%$ and $18 \%$ for US-283 and $12 \%$ and $16 \%$ for US- 160

The analysis of the moisture content data collected using the TDR gages leads to the following inferences regarding variation of subgrade moisture content under pavements in Kansas:

a) The pavements in this climatic area experience relatively constant moisture condition under paved surfaces for most of the locations during most of the year with the northeast part of the state showing a slightly higher variation than the southwest part. Overall, the moisture content changed about 3 to $6 \%$.

b) Although most of subgrade moisture content readings were constant over one year period, quite a few readings showed significant variation during short periods of time suggesting extremes for those sites, especially in northeast Kansas. This indicates the necessity for better drainage requirements for the pavements in northeast Kansas than in southwest Kansas.

c) Variation of subgrade moisture content does not appear to depend on precipitation only. This might be due to the phase lag between soil moisture content and precipitation. For pavements in southwestern Kansas, moisture contents during months with higher precipitation exceeded moisture contents during spring thaw periods. This indicates that for Kansas condition, variation in subgrade response in summer may be much more than that in spring.

\section{Backcalculation of Subgrade Layer Moduli}

A linear elastic analysis backcalculation program, MODULUS (Scullion and Michalak 1991), was used to backcalculate the subgrade moduli from the FWD deflection basins. The deflection basins corresponding to the target loading of $40 \mathrm{kN}$ were used in this study. The pavements were modeled as two-layer systems with an 
asphalt concrete layer and a subgrade layer since they did not have a base course. No depth values to bedrock were specified for MODULUS and the program computed a depth value automatically in order to minimize the error between measured and calculated deflections.

In the MODULUS backcalculation system, Boussinesq's equation for deflection under a point load is used to determine the surface location at which the measured deflection is fully contributed by the subgrade. At each sensor the apparent Young's modulus $E_{r}$ of the infinite half space is calculated by:

$$
E_{r}=\frac{P\left(1-\mu^{2}\right)}{\pi r D_{r}}
$$

where:

$$
\begin{array}{ll}
\mathrm{D}_{\mathrm{r}}= & \text { Surface deflection at offset } \mathrm{r} \text { due to load } \mathrm{P} ; \\
\mathrm{P}= & \text { Point load; } \\
\mu= & \text { Poisson's ratio; and } \\
\mathrm{r}= & \text { Horizontal offset from the load }
\end{array}
$$

The MODULUS system assumes that in most cases, the subgrade stiffness increases with depth and distance from the load. At the inner sensors, the calculated $E_{r}$ is higher due to the influence of the upper layers and thus, the plot of $E_{r}$ with various sensor offsets usually shows a downward parabola. As a result, MODULUS removes those sensors which are beyond the sensor position giving the lowest $E_{r}$ value and uses only select sensors to minimize the backcalculation error

\section{Effect of Subgrade Moisture Contents on Backcalculated Subgrade Moduli}

Figure 3 shows the variation of the backcalculated subgrade moduli with the measured moisture content. The moduli are the mean of the ten individual station location values. It is generally assumed that the increase in moisture content should lead to higher subgrade deflections and poorer subgrade response. However, the assumption does not appear to be fully valid here. No clear dependency of the backcalculated subgrade modulus on the soil moisture content can be observed. This indicates that the temperature variable may be the most decisive factor of influence on subgrade response in pavement system over season, since subgrade is an unbound layer with stress-dependent behavior. Temperature affects the stiffness of the asphalt concrete (AC) layer in the pavement structure. These changes may in turn affect the deviator and bulk stresses in the subgrade and finally, subgrade modulus.

For $\mathrm{K}-18$, the results show that the highest subgrade modulus was obtained at about $21.5 \%$ moisture probably, the optimum moisture content on this site. Lower 
moduli values were obtained when moisture contents were higher or lower than this value. The subgrade modulus on $\mathrm{K}-113$ appeared to be variable in a very narrow range of moisture content (16 to $20 \%$ ), however, a maximum modulus value corresponding to an optimum moisture content could not be observed since no FWD tests were performed for moisture contents between 20 and 25 percent. The sites on US-160 and US-283 show that the pattern of variation of the combined subgrade moduli with the average subgrade moisture content displays a somewhat sine shape, but again, not clearly.

\section{Seasonal Variation of Backcalculated Subgrade Moduli}

Figure 4 shows the variation of backcalculated subgrade moduli and associated average pavement temperatures during FWD tests for the pavements under study. The moduli values, the average of moduli computed at ten stations, varied over seasons. The coefficients of variation of the subgrade moduli for ten stations over the seasons are shown in Table 2. Coefficients of variation between $7 \%$ (US-283) and $29 \%$ (K-113) were observed. Higher values were always observed for the sites in northeast Kansas.

The statistical correlation analysis between the backcalculated subgrade modulus and the average pavement temperature at the time of the FWD deflection tests indicated a linear correlation coefficient between -0.68 and -0.75 . This indicates that the subgrade modulus decreases with an increase in asphalt layer temperature. The decreasing subgrade moduli with increasing pavement temperature can be explained in terms of stress-dependent behavior of cohesive soil material. The AC surface layer acts as a buffer between the FWD load and the subgrade layer, and it is well known that asphalt concrete layer stiffness is strongly affected by temperature. When the temperature is higher, the AC layer softens, which in turn increases the deviator stress acting on the subgrade. The resilient modulus of cohesive soil (such as clay) decreases as the deviator stress increases. When the temperature is lower, the situation would be just opposite. It is clear from this discussion that some variabilities in backcalculated subgrade moduli can be avoided by conducting FWD tests in a moderate temperature regime.

\section{Effect of Site Variability Versus Seasonal Variation}

The seasonal variations (in terms of the coefficients of variation) of the measured deflections, backcalculated layer moduli as well as the climatic variables for all sites have been shown in Table 3 . The values have been averaged based on the geographical location of the sites (southwest and northeast). As expected, the climatic variables show the highest variabilities followed by the backcalculated asphalt concrete moduli. The values in the third column are the coefficients of variation for the first sensor deflections corrected for temperature for all stations of the sites. The 
deflections have been corrected using the algorithm suggested by AASHTO (1993). The second column tabulates the uncorrected values. It is apparent that for the northeast Kansas sites, on average, $27 \%$ variation in deflection remains even after correction for temperature. The average variation of subgrade moduli is around $11 \%$ suggesting that the variations other than subgrade are also significant. These variables may include the AASHTO temperature correction factors, thickness of the pavement surface layer, spatial variation in the property of asphalt concrete materials, etc. The variation in backcalculated subgrade modulus is clearly a function of temperature much like the variations of the first sensor deflections and the asphalt moduli as shown for the northeast Kansas sites in Figure 5. These effects are more pronounced in southwest Kansas where temperature variations are higher than in northeast Kansas as shown in Figure 6. However, the variations in precipitation are similar.

Table 4 shows the individual months of the highest spatial variation for all sites along with the values of the parameters discussed in Table 3 . All higher variations are associated with the extreme temperature conditions, low average pavement temperature in most of the cases. In all cases, the precipitation was nominal thereby excluding this climatic variable as a major factor. This leaves the average pavement temperature as the only significant factor in determining the variability of the deflection values. It is clear that both high and low temperature may result in higher variabilities across the site. For asphalt concrete, the effect is pronounced on the first sensor deflection and in turn, backcalculated asphalt concrete moduli. For example, $\mathrm{K}-18$ has the highest first sensor deflection and the lowest backcalculated asphalt concrete moduli during early March when it showed the highest spatial variation in deflection. Similar trends were also observed for US-283.

The spatial and seasonal variabilities of backcalculated subgrade moduli were also investigated by using the Analysis of Variance (ANOVA) statistical technique. The number of independent variables defining the subset was the order of the interaction. The hypothesis tested is that the mean value of the dependent variable (subgrade modulus) is the same for all subsets having the same level of the independent variables. Table 5 presents the results of the ANOVA analysis. Low probability values indicate that the independent variable has a strong effect on the value of the dependent variable. Thus, the p-values for US-160 and US-283 indicate that the station location has a stronger influence on the backcalculated subgrade moduli than the season. The backcalculated subgrade moduli on K-113 is highly influenced by the season, and less influenced by the FWD test location, while for K18 , both season and station location have significant effect on backcalculated subgrade moduli. The high p-values obtained for the second order interaction (Location*Season term) indicate that the seasonal effects are very similar at all locations. Thus both location and season strongly affect the values of the backcalculated subgrade moduli, and the seasonal and spatial variations are comparable. 


\section{Conclusions}

Based on the analysis shown above the following conclusions can be drawn about the temperature and moisture effect on backcalculated layer moduli:

1. The pavements in Kansas experience relatively constant moisture condition under paved surfaces for most of the locations during most of the year with the northeast part of the state showing a slightly higher variation than the southwest part. Overall, the moisture content changed about 3 to $6 \%$.

2. For almost all sites, the patterns of subgrade moduli versus season, showed sine-shaped forms. This indicates that the temperature may affect the "backcalculated" subgrade moduli since subgrade is an unbound layer that may show stress-dependent behavior and its modulus would vary with the deviator stress. This was confirmed by the higher coefficient of correlation between the backcalculated subgrade moduli and temperature parameters during FWD tests.

3. The backcalculated subgrade moduli were lower whenever the deflections were measured by the FWD at higher pavement surface temperature. It is presumed that this was due to violation of the linearity assumption due to variable deviator stresses on the subgrade since temperature significantly affect the measured pavement deflections. The subgrade moisture may have some effect for asphalt pavements in certain months of the year but is masked by the dominant temperature effect in all cases.

4. The analysis of variance (ANOVA) indicated that both seasonal and site variabilities can be significant. For most pavements, seasonal variabilities are usually higher than site variabilities. After correction for temperature, variations in deflections and moduli become approximately equal to the site variabilities which was also confirmed by ANOVA.

5. The highest seasonal variation is associated with temperature, not precipitation. Also, extreme test temperatures, both high and low, result in higher variation of measured deflections and subsequently, backcalculated subgrade moduli across a site. Thus, some variabilities in backcalculated subgrade moduli can be minimized by conducting FWD tests in a moderate temperature regime 
References

AASHTO (1993). AASHTO Guide for Design of Pavement Structures., American Association of State Highway and Transportation Officials, Washington, D.C.

Gisi, A.J. (1982). Seasonal Adjustments for Flexible Pavement Deflections.

Term Paper Submitted to the Dept. of Civil Engineering, Kansas State

University, Manhattan.

Haas, R., W.R. Hudson and J.P. Zaniewski (1994). Modern Pavement

Management. Krieger Publishing Co., Malabar, FL.

Hossain M., Long B., Kotwala S. J. (1996). Seasonal and Hourly Variation of

Pavement Deflections Measured with the Falling Weight Deflectometer

K-TRAN Report: KSU-94-3, Kansas Department of Transportation, Topeka, August.

Richter, C.A. (1991). "Seasonal Monitoring of Pavements - A Whole Lot More". Proceedings of the Conference on Road and Pavement Response Monitoring Systems, ASCE, New York, pp. 182-195.

Scullion T. and C. Michalak (1991). MODULUS 4.0, User's Manual, Report

FHWA/TX-88/1123- 4, Texas Transportation Institute, Texas A\&M

University, College Station, January. 


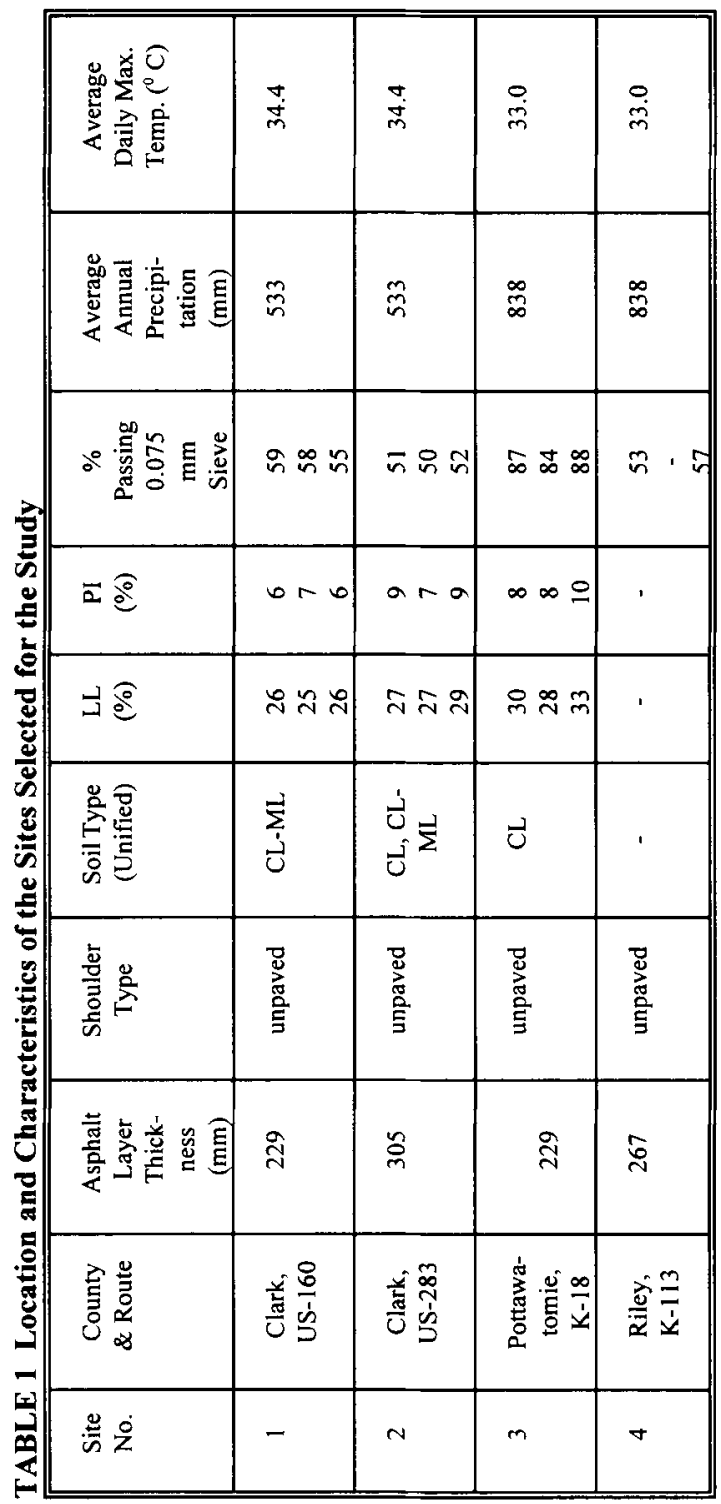


TABLE 2 Seasonal Variation of Subgrade Moduli

\begin{tabular}{|c|c|c|c|c|}
\hline \multirow{2}{*}{ Site } & \multicolumn{2}{|c|}{ Mean (MPa) } & \multicolumn{2}{c|}{ Coefficient. of Variation (\%) } \\
\cline { 2 - 5 } & Minimum & Maximum & Minimum & Maximum \\
\hline K-18 & 86 & 131 & 10 & 21 \\
\hline K-113 & 247 & 353 & 11 & 29 \\
\hline US-160 & 126 & 170 & 7 & 16 \\
\hline US-283 & 143 & 180 & 7 & 17 \\
\hline
\end{tabular}

TABLE 3 Seasonal Variations of Different Pavement Response and Climatic Parameters

\begin{tabular}{|c|c|c|c|c|c|c|}
\hline \multirow[t]{2}{*}{ Site } & \multicolumn{6}{|c|}{ Coefficient of Variation (\%) } \\
\hline & K-18 & $\mathrm{K}-113$ & $\begin{array}{l}\text { Avg. NE } \\
\text { Kansas }\end{array}$ & US- 160 & US-283 & $\begin{array}{c}\text { Avg.SW } \\
\text { Kansas }\end{array}$ \\
\hline $\begin{array}{l}\text { Uncorrected } \\
1^{\text {st }} \text { Sensor } \\
\text { Deflection }\end{array}$ & 31 & 27 & 29 & 41 & 41 & 41 \\
\hline $\begin{array}{l}\text { Corrected } \\
1^{\text {st }} \text { Sensor } \\
\text { Deflection }\end{array}$ & 26 & 29 & 27 & 35 & 38 & 36 \\
\hline AC Modulus & 76 & 45 & 61 & 69 & 66 & 67 \\
\hline $\begin{array}{l}\text { Corrected AC } \\
\text { Modulus }\end{array}$ & 32 & 21 & 27 & 63 & 53 & 58 \\
\hline Subgrade Modulus & 12 & 11 & 12 & 24 & 8 & 16 \\
\hline $\begin{array}{l}\text { Average Pavement } \\
\text { Temperature }\end{array}$ & 30 & 32 & 31 & 46 & 49 & 48 \\
\hline $\begin{array}{c}\text { Surface } \\
\text { Temperature }\end{array}$ & 36 & 34 & 35 & 48 & 58 & 53 \\
\hline Air Temperature & 28 & 25 & 22 & 35 & 38 & 37 \\
\hline Precipitation & 108 & 108 & 108 & 112 & 112 & 112 \\
\hline
\end{tabular}


TABLE 4 Months of Highest Spatial Variations at Various Sites and Corresponding Pavement Responses and Climatic Parameters

\begin{tabular}{|c|c|c|c|c|}
\hline & \multicolumn{4}{|c|}{ Site \& Maximum Variation (\%) } \\
\hline & $\begin{array}{c}K-18 \\
(38 \%)\end{array}$ & $\begin{array}{l}\mathrm{K}-113 \\
(70 \%)\end{array}$ & $\begin{array}{l}\text { US- } 160 \\
(37 \%)\end{array}$ & $\begin{array}{c}\text { US-283 } \\
(16 \%)\end{array}$ \\
\hline Month & $\begin{array}{l}\text { March } \\
\text { (early) }\end{array}$ & $\begin{array}{l}\text { March } \\
\text { (early) }\end{array}$ & June & $\begin{array}{l}\text { March } \\
\text { (early) }\end{array}$ \\
\hline $1^{\text {st }}$ Sensor Deflection $(\mathrm{mm})$ & 0.49 & 0.12 & 0.44 & 0.15 \\
\hline $\begin{array}{l}\text { Corrected } 1^{\text {st }} \text { Sensor } \\
\text { Deflection }(\mathrm{mm})\end{array}$ & 1.17 & 0.22 & 0.31 & 0.46 \\
\hline Average AC Modulus (MPa) & 1034 & 11,614 & 1,441 & 5,413 \\
\hline $\begin{array}{l}\text { Corrected Average } \\
\text { AC Modulus (MPa) }\end{array}$ & 352 & 8,131 & 3,241 & 1,621 \\
\hline $\begin{array}{l}\text { Average Subgrade Modulus } \\
\text { (MPa) }\end{array}$ & 116 & 76 & 138 & 174 \\
\hline $\begin{array}{l}\text { Average Pavement } \\
\text { Temperature }\left({ }^{\circ} \mathrm{C}\right)\end{array}$ & 36.5 & 32 & 31 & 27.8 \\
\hline Surface Temperature $\left({ }^{\circ} \mathrm{C}\right)$ & 47 & 34 & 29 & 24 \\
\hline Air Temperature $\left({ }^{\circ} \mathrm{C}\right)$ & 40 & 25 & 22 & 47 \\
\hline Precipitation (mm) & 51 & 51 & 229 & 279 \\
\hline
\end{tabular}

TABLE 5 Results of the ANOVA Analysis

\begin{tabular}{|l|l|c|c|c|c|}
\hline \multirow{2}{*}{ Variable } & \multirow{2}{*}{ Test } & \multicolumn{4}{|c|}{ Site } \\
\cline { 3 - 6 } & & K-113 & K-18 & US-160 & US-283 \\
\hline \multirow{2}{*}{ Station Location } & $\mathrm{F}$ & 0.04 & 70.65 & 16.97 & 49.73 \\
\cline { 2 - 6 } & p-value & 0.84 & 0 & 0 & 0 \\
\hline \multirow{2}{*}{ Season } & $\mathrm{F}$ & 0.79 & 18.8 & 0.12 & 0.13 \\
\cline { 2 - 6 } & p-value & 0.37 & 0 & 0.727 & 0.715 \\
\hline \multirow{2}{*}{$\begin{array}{l}\text { Station } \\
\text { Location*Season }\end{array}$} & F & 0.01 & 1.25 & 0.01 & 0.17 \\
\cline { 2 - 6 } & p-value & 0.904 & 0.265 & 0.99 & 0.68 \\
\hline
\end{tabular}




\section{Shroce MtistureCartert}

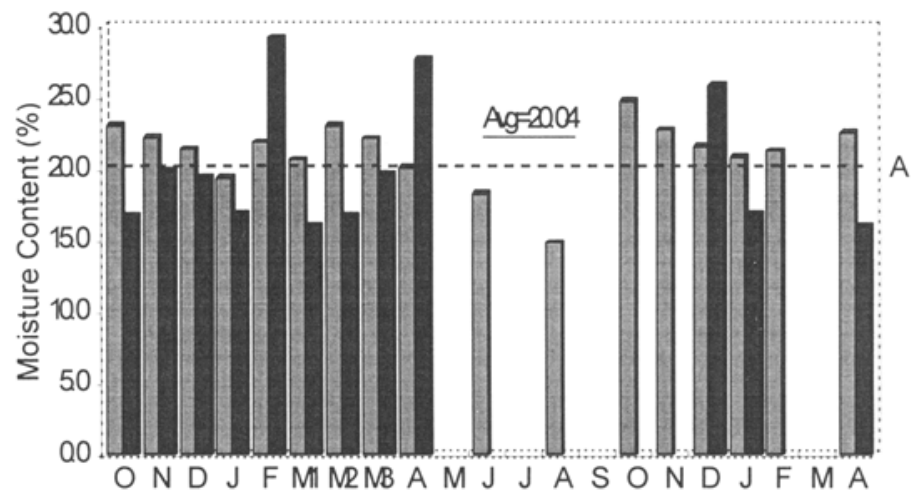

Mrth

$\square \mathrm{K}-18 \mathrm{~K}-113$

Figure 1. Seasonal Variation of Subgrade Moisture Contents for the Northeast Kansas Sites

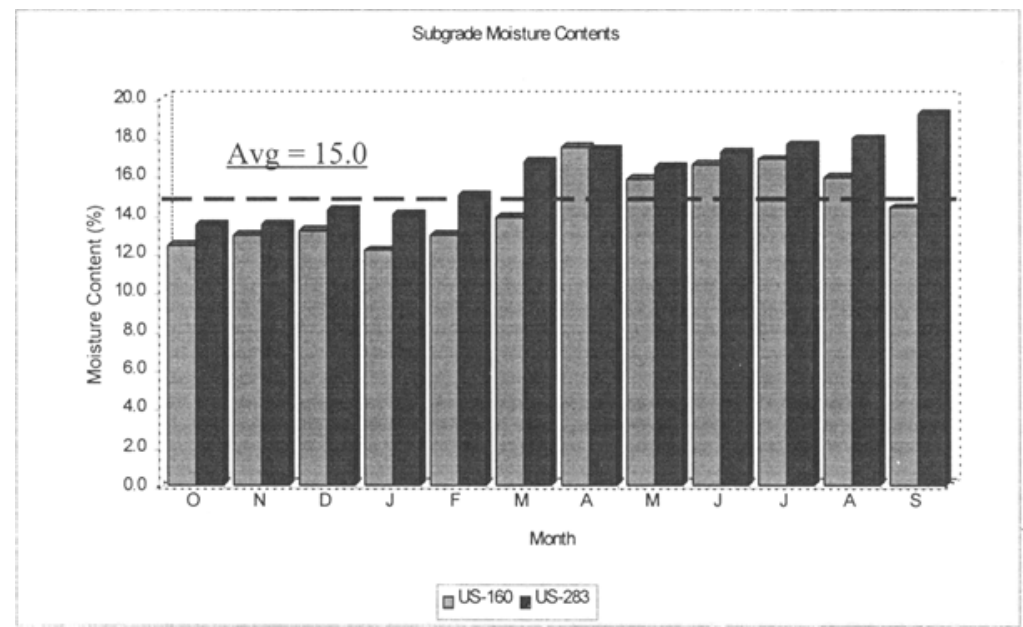

Figure 2. Seasonal Variation of Subgrade Moisture Contents for the Southwest Kansas Sites 


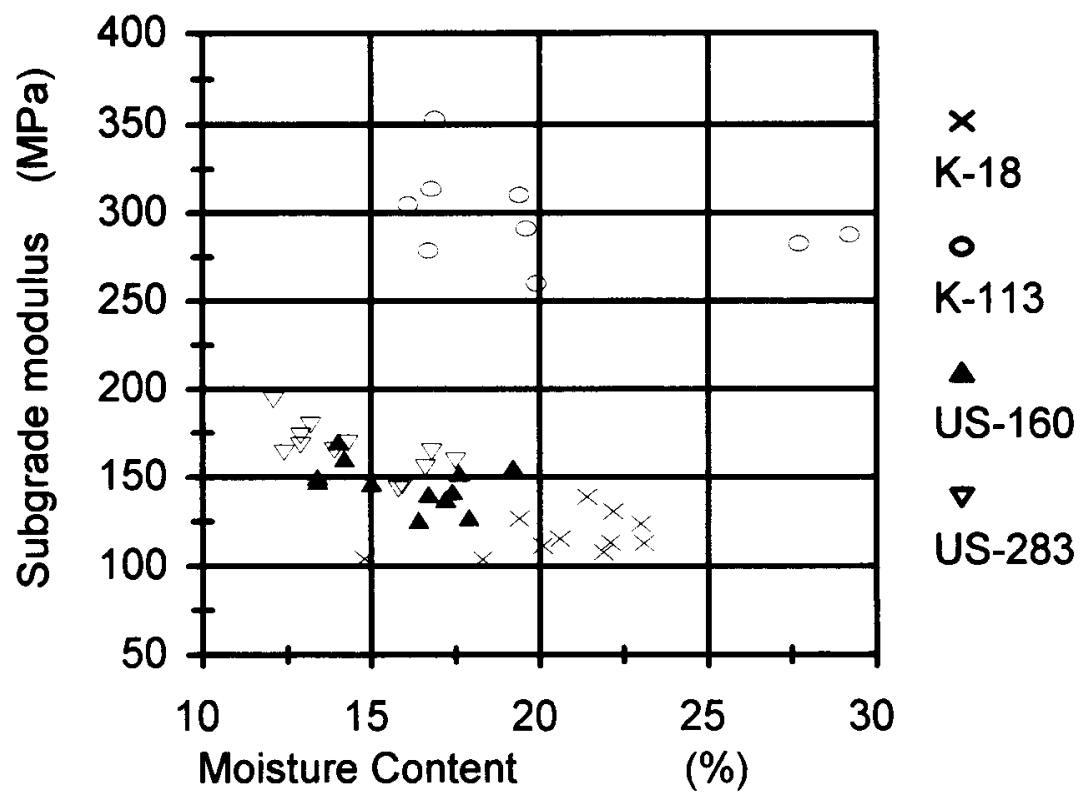

Figure 3. Subgrade Modulus vs Moisture Content 


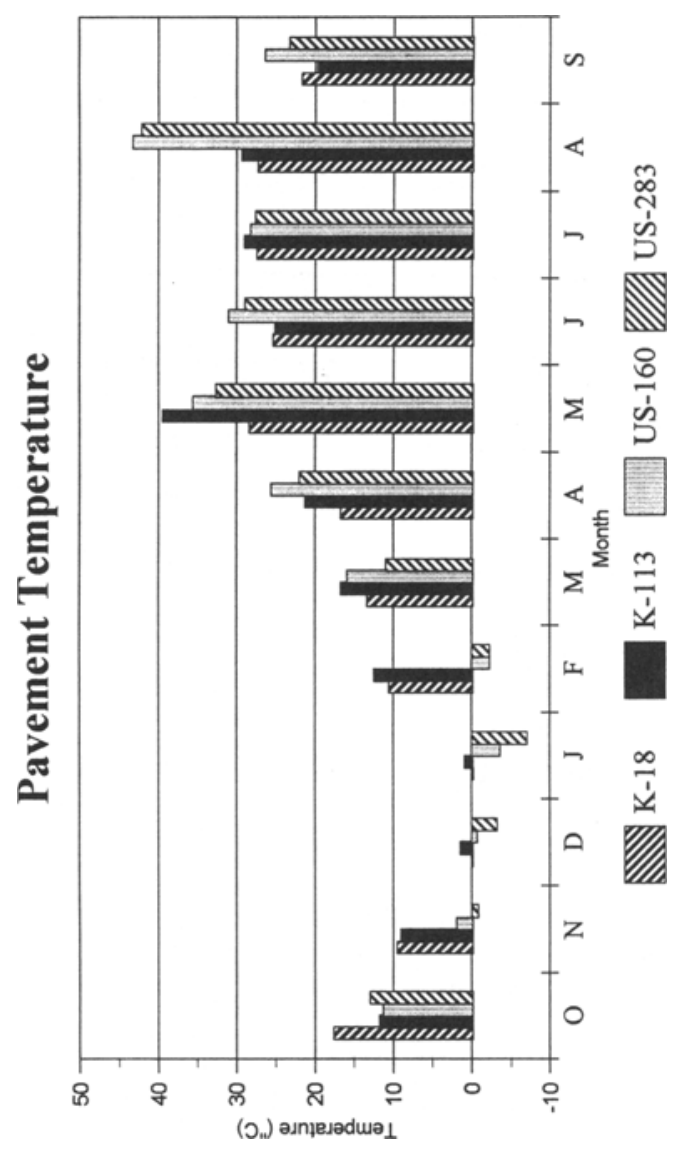

Pavement Subgrade, Unbound Materials, and Nondestructive Testing 


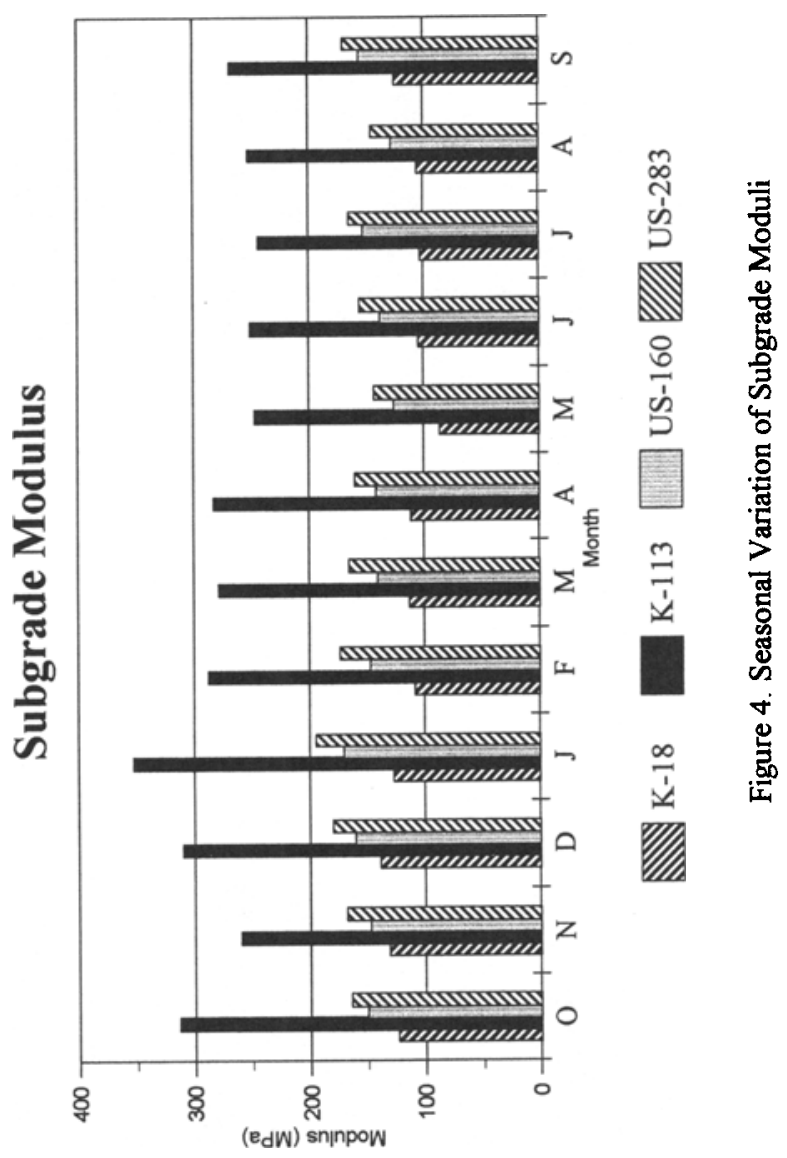




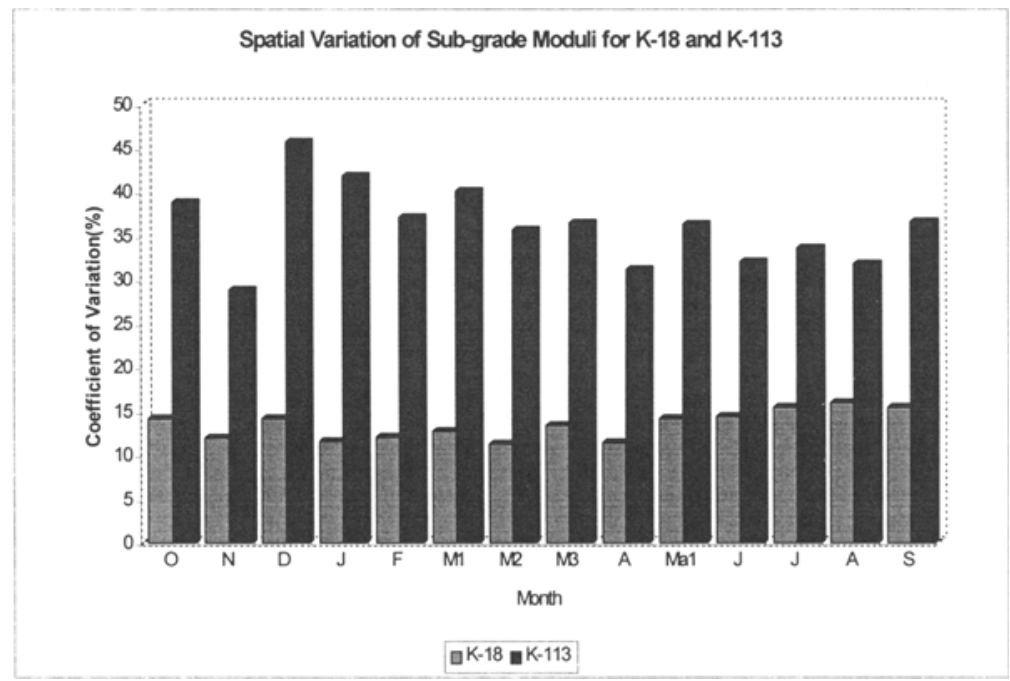

Figure 5. Spatial Variation of Subgrade Moduli for the Northeast Kansas Sites

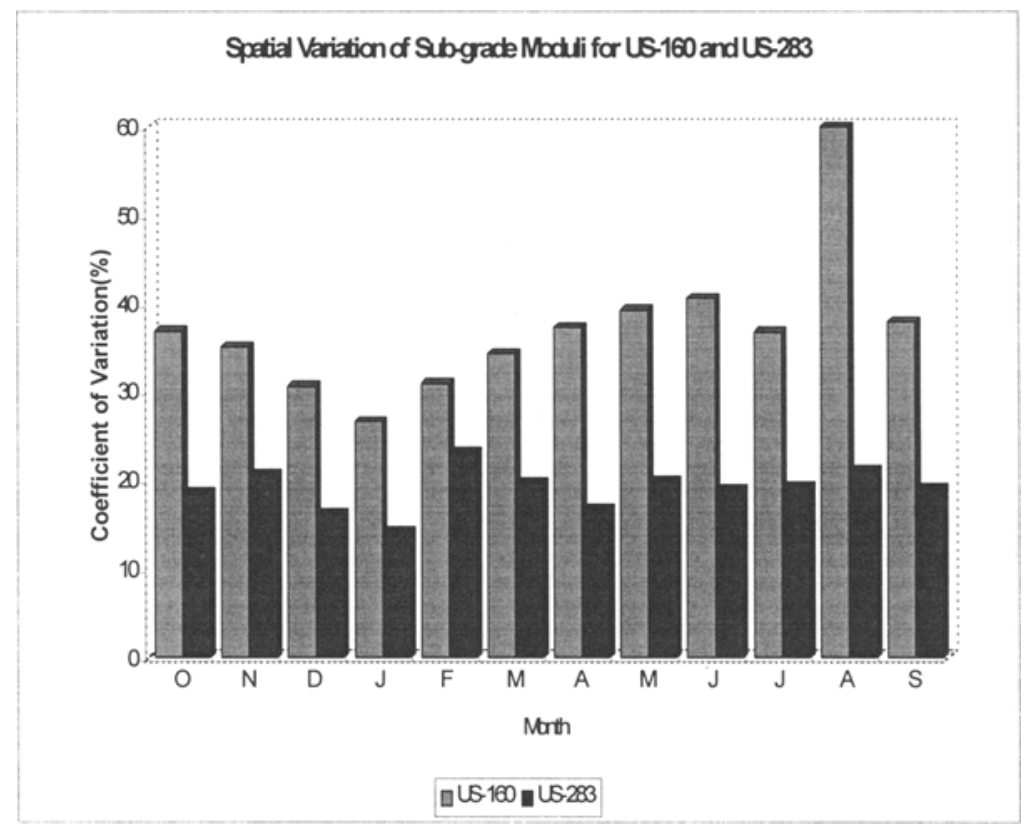

Figure 6. Spatial Variation of Subgrade Moduli for the Southwest Kansas Sites 